\title{
Comprometimento da organização sensorial em pacientes com migrânea com e sem aura e migrânea crônica - estudo controlado
}

\author{
Carina Ferreira Pinheiro' ${ }^{1}$, Gabriela Ferreira Carvalho ${ }^{2}\left(\mathbb{D}\right.$, Renato Moraes ${ }^{1}$,

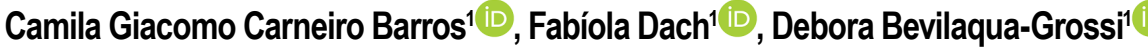

'Faculdade de Medicina de Ribeirão Preto, Universidade de São Paulo, Ribeirão Preto, São Paulo, Brasil.

${ }^{2}$ University of Luebeck, Alemanha

\begin{abstract}
Introdução
A literatura sugere que os déficits de equilíbrio observados em pacientes com migrânea estão relacionados à presença de aura e alta frequência de crises. Além disso, sintomas vestibulares também são altamente prevalentes nesses pacientes. Do ponto de vista neurofisiológico, a contribuição de cada um dos sistemas que controlam o equilíbrio ainda não é conhecida nestes pacientes.
\end{abstract}

\section{Objetivos}

Investigar se pacientes com diferentes subtipos de enxaqueca apresentam comprometimento da organização sensorial do equilíbrio, em contraste com indivíduos sem cefaleia.

\author{
Material e métodos \\ Estudo transversal, que avaliou mulheres entre 18 e 55 anos. Pacientes com diagnóstico de migrânea foram distri- \\ buídos em três grupos: migrânea com aura $(n=30)$, migrânea sem aura $(n=30)$ e migrânea crônica $(n=30)$. \\ Mulheres sem dor de cabeça formaram o grupo controle $(n=30)$. A avaliação do equilíbrio foi realizada com o Teste \\ de Organização Sensorial (TOS). Provas de função vestibular foram realizadas em todas as participantes. $O$ estudo \\ foi aprovado pelo comitê de ética em pesquisa (CAAE 62695916.5.0000.5440).
}

\section{Resultados \\ O escore final do TOS e os escores referentes a cada sistema sensorial foram comparados entre os grupos com modelo linear multivariado $(p<0,05)$. $O$ escore final do TOS foi menor nos pacientes com migrânea em relação aos controle, e naqueles com aura e migrânea crônica em relação aos migranosos sem aura $(p<0,05)$. Pacientes com aura e migrânea crônica apresentaram maior comprometimento dos sistemas vestibular e visual, e os com aura também do sistema somatossensorial $(p<0,05)$. Não houve diferença entre os grupos quanto às provas de função vestibular $(p>0,05)$.}

\section{Conclusão}

Apesar da ausência de diferenças nos testes otoneurológicos, a presença de aura e maior frequência de crises de cefaleia estão relacionadas ao comprometimento do equilíbrio com a manipulação dos estímulos sensoriais. Os sistemas vestibular e visual devem ser considerados no atendimento clínico.

Palavras-chave: Transtornos de Enxaqueca, Fenômenos Biomecânicos, Equilíbrio Postural.

Financiamento: FAPESP (processo 2015/18031-5) 